\title{
SDR Input Power Estimation Algorithms
}

\author{
Jennifer Nappier \\ NASA Glenn Research Center, Cleveland, Ohio
}

Co-Author: Janette Briones

NASA Glenn Research Center, Cleveland, Ohio

\author{
IEEE Aerospace \\ March 2013
}




\section{Presentation Contents}

- Background Information

- SCaN Testbed System Overview

- GD SDR Description

- Motivation for SDR Input Power Estimator

- Automatic Gain Control Characterization Results

- SDR Input Power Estimator Descriptions

- Straight Line

- Adaptive Linear Combiner

- Neural Network

- Estimator Error Analysis

- On-orbit Testing Experimental Results

- Summary / Future Work 


\section{BACKGROUND INFORMATION}




\section{Space Communication and Navigation (SCaN) Testbed Flight System Overview}

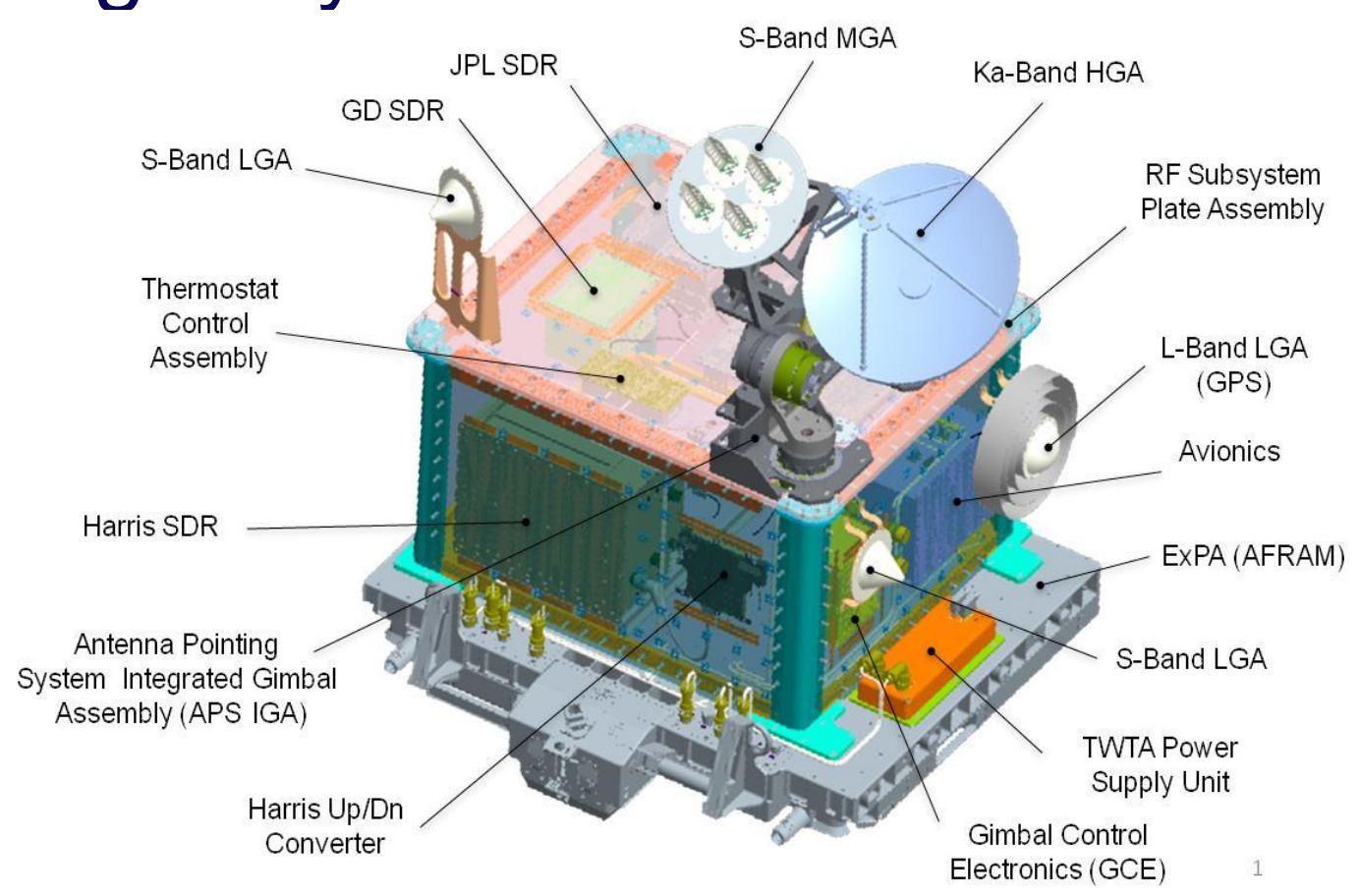

- Medium gain S-band and Electronics (GCE) Ka-band antenna on antenna pointing subsystem.

- Antenna pointing system

- Flight Computer/Avionics

- Launched on Japanese HTV-3 on July 20, 2012

- Installed on ISS August 7, 2012

- Checkout and Commissioning is in progress 
Pictures of Installation and First Operations
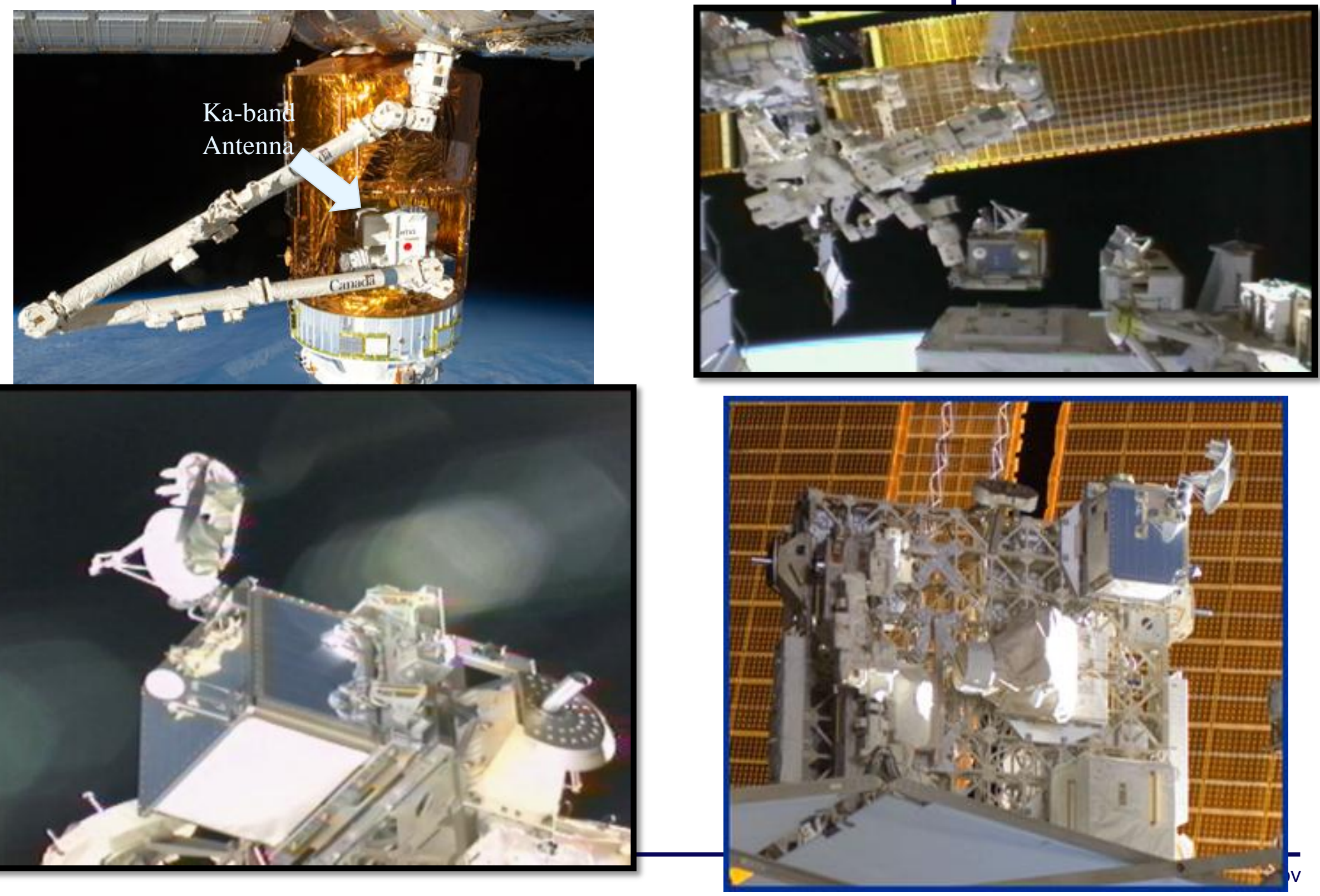


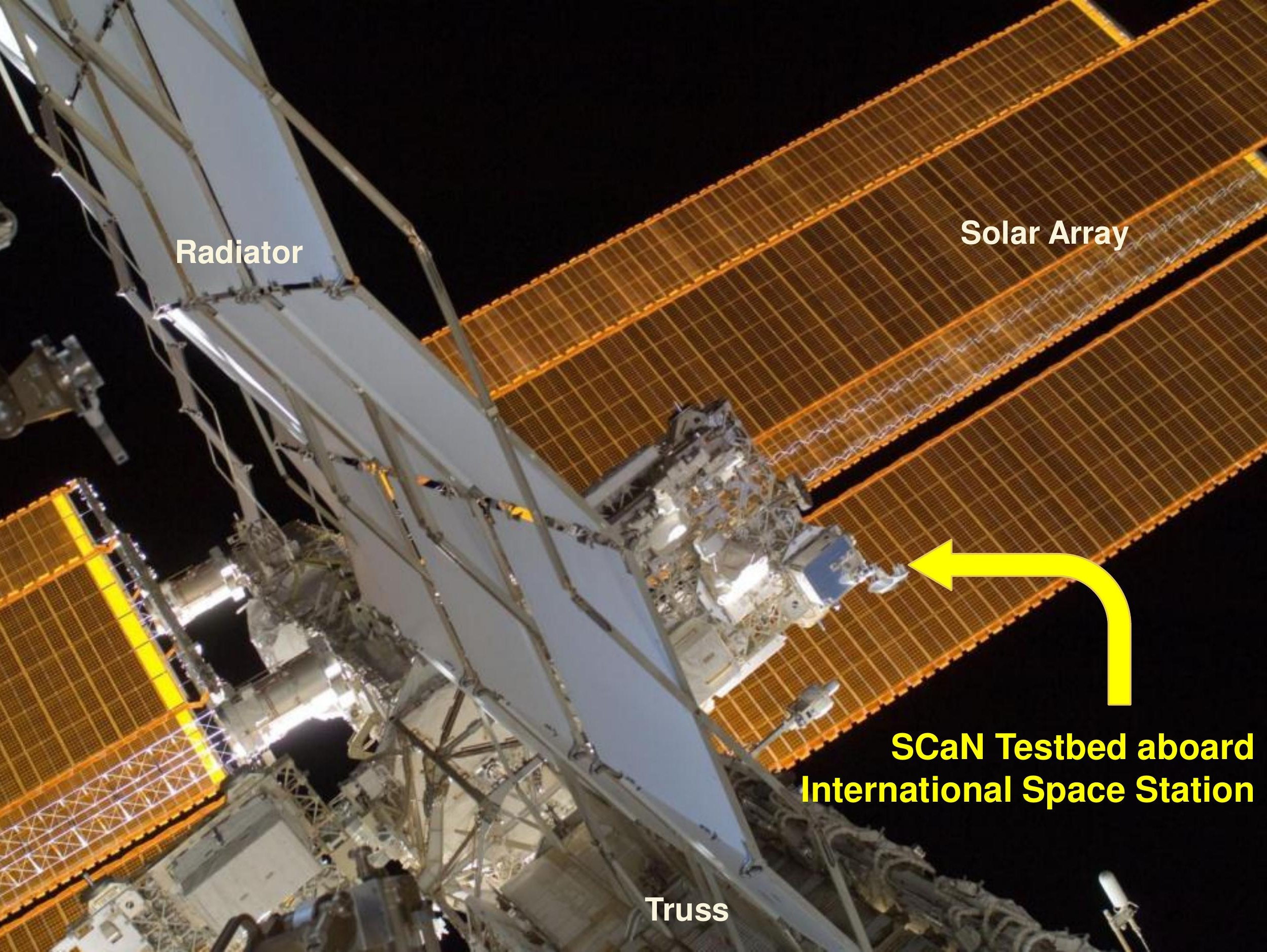




\section{SCaN Testbed Experiment System}

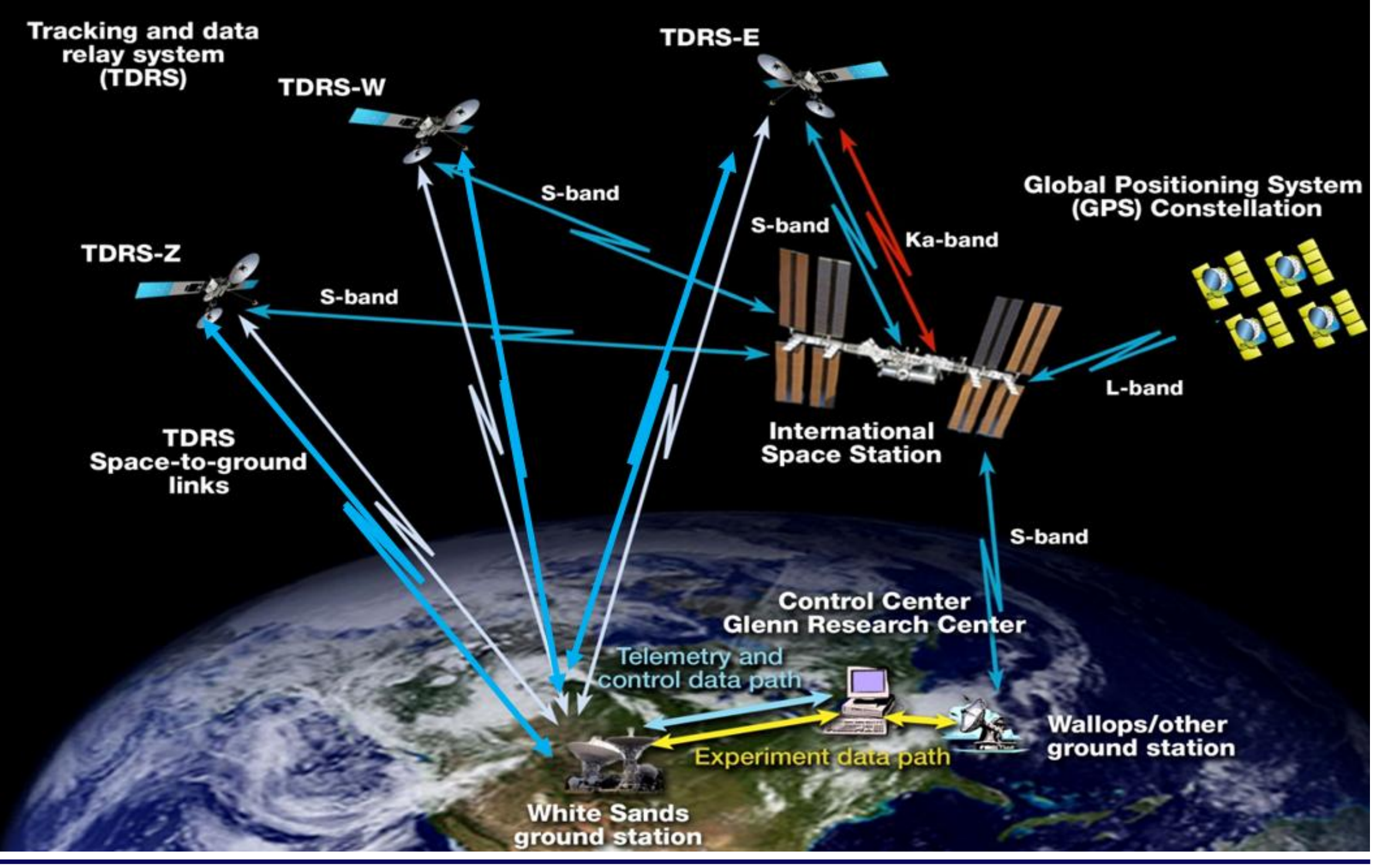




\section{SCaN Testbed General Dynamics SDR Description}

- TDRSS S-band Transponder

- 8 receive waveform configurations

- 30 transmit waveform configurations

- 1 Xilinx Virtex II QPro FPGA, 3 M gate

- ColdFire microprocessor

- Analog and Digital automatic gain controls (AGCs)

\begin{tabular}{|c|c|c|c|}
$\begin{array}{c}\text { Waveform } \\
\text { Number }\end{array}$ & \multicolumn{1}{c}{$\begin{array}{c}\text { Center } \\
\text { Frequency } \\
\text { (GHz) }\end{array}$} & $\begin{array}{c}\text { Data Rate } \\
\text { (kbps) }\end{array}$ & $\begin{array}{c}\text { Forward } \\
\text { Error } \\
\text { Correction }\end{array}$ \\
\hline $\mathbf{1}$ & SA & 18 & Coded \\
\hline $\mathbf{2}$ & SA & 18 & Uncoded \\
\hline $\mathbf{3}$ & SA & 72 & Coded \\
\hline $\mathbf{4}$ & SA & 72 & Uncoded \\
\hline $\mathbf{5}$ & MA & 18 & Coded \\
\hline $\mathbf{6}$ & MA & 18 & Uncoded \\
\hline $\mathbf{7}$ & MA & 72 & Coded \\
\hline $\mathbf{8}$ & MA & 72 & Uncoded \\
\hline
\end{tabular}

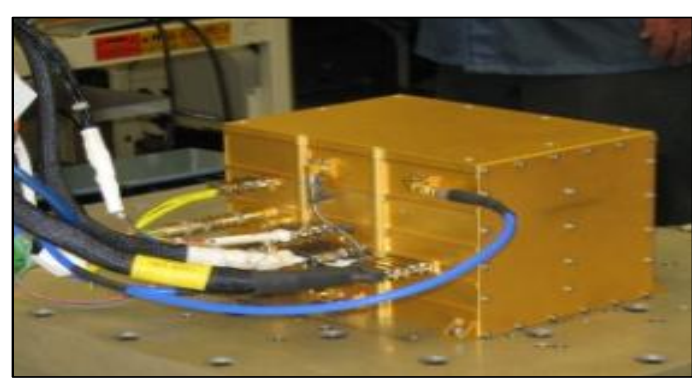

- TDRSS: Tracking Relay Data Satellite System

- SA: Single Access

$(2.041 \mathrm{GHz})$

- MA: Multiple Access

$(2.106 \mathrm{GHz})$ 


\section{SDR Input Power Estimators Description}

\section{Motivation}

- The received power can be used to characterize and estimate link performance

- The estimated link performance can be used to update predicted performance calculated from link budgets

- GD SDR did not implement an SDR input power estimator

\section{Expected On-orbit Operating Conditions}

- SDR Input Power Range: $-130 \mathrm{dBm}$ to $-100 \mathrm{dBm}$

- Temperature: $-15{ }^{\circ} \mathrm{C}$ to $+45^{\circ} \mathrm{C}$

\section{Estimator Method}

- Utilize digital and analog AGCs and baseplate temperature to estimate SDR input power 


\section{AGC Characterization Results at Ambient Temperature}

\section{Analog AGC at $26^{\circ} \mathrm{C}$}

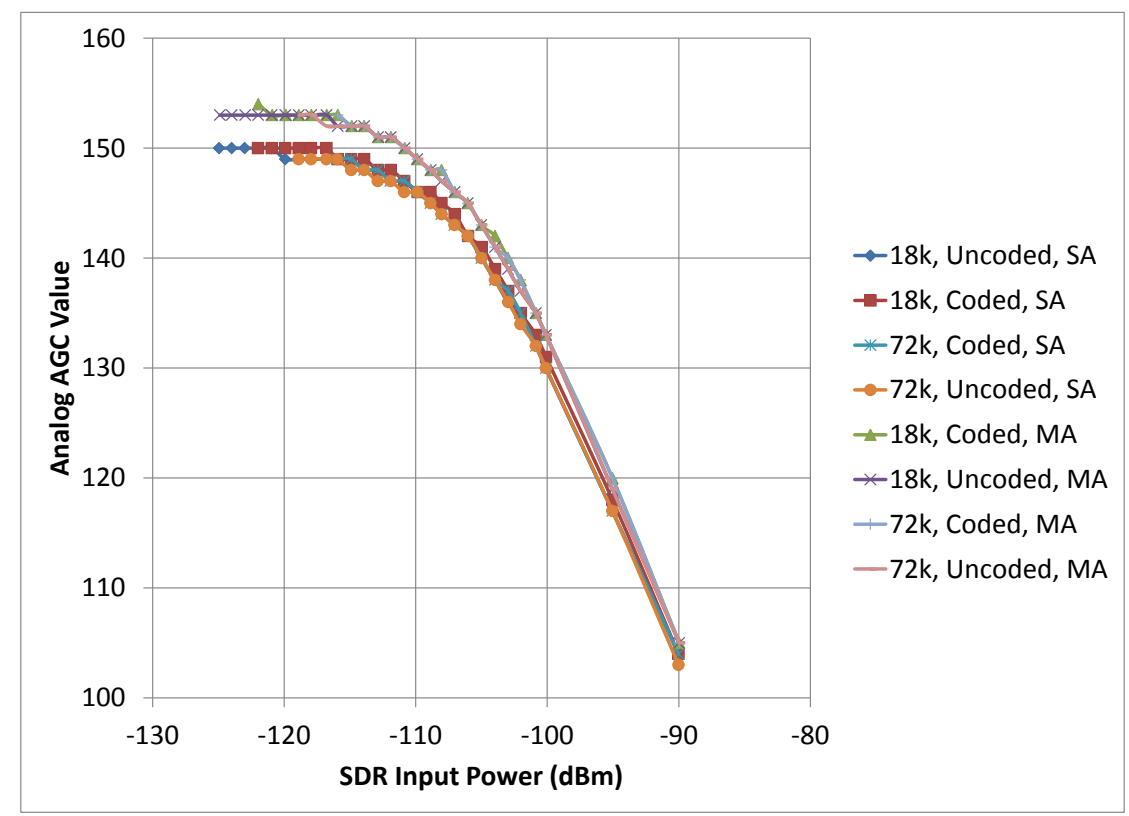

\section{Digital AGC at $26^{\circ} \mathrm{C}$}

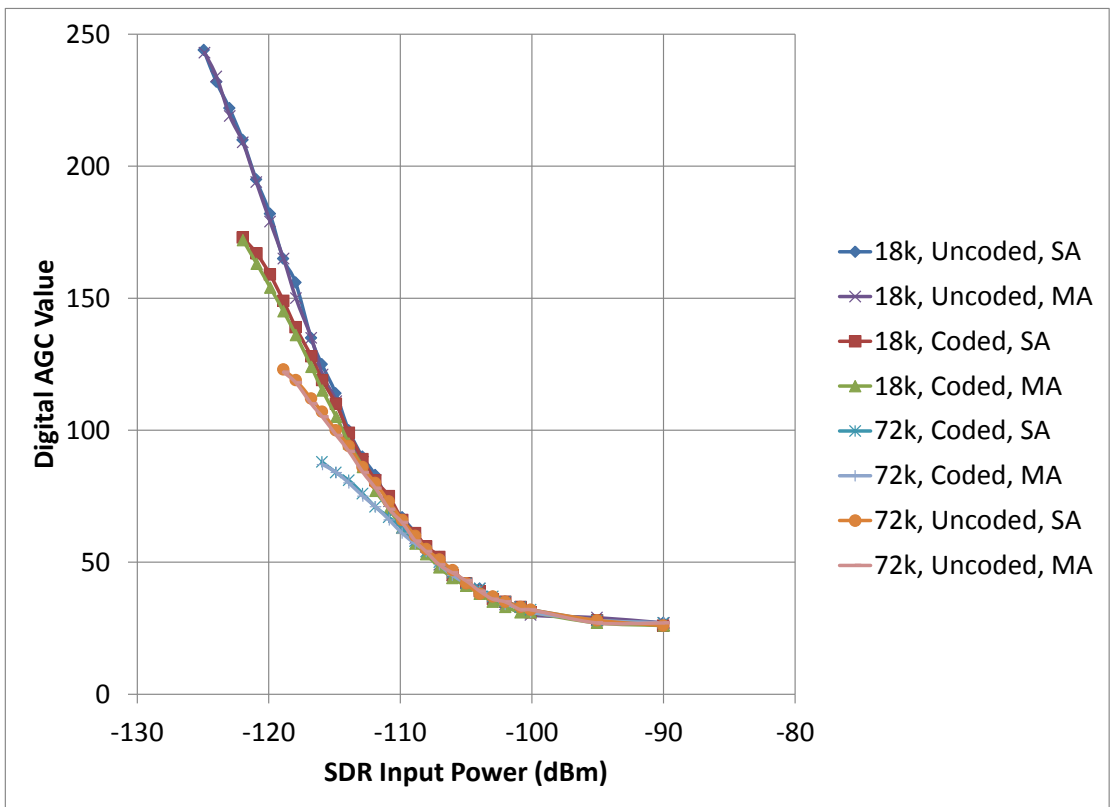

- Analog AGC varies with center frequency (MA/SA)

- Digital AGC varies with symbol rate (coding + data rate) 


\section{AGC Characterization Results over Temperature}

\section{Analog AGC}

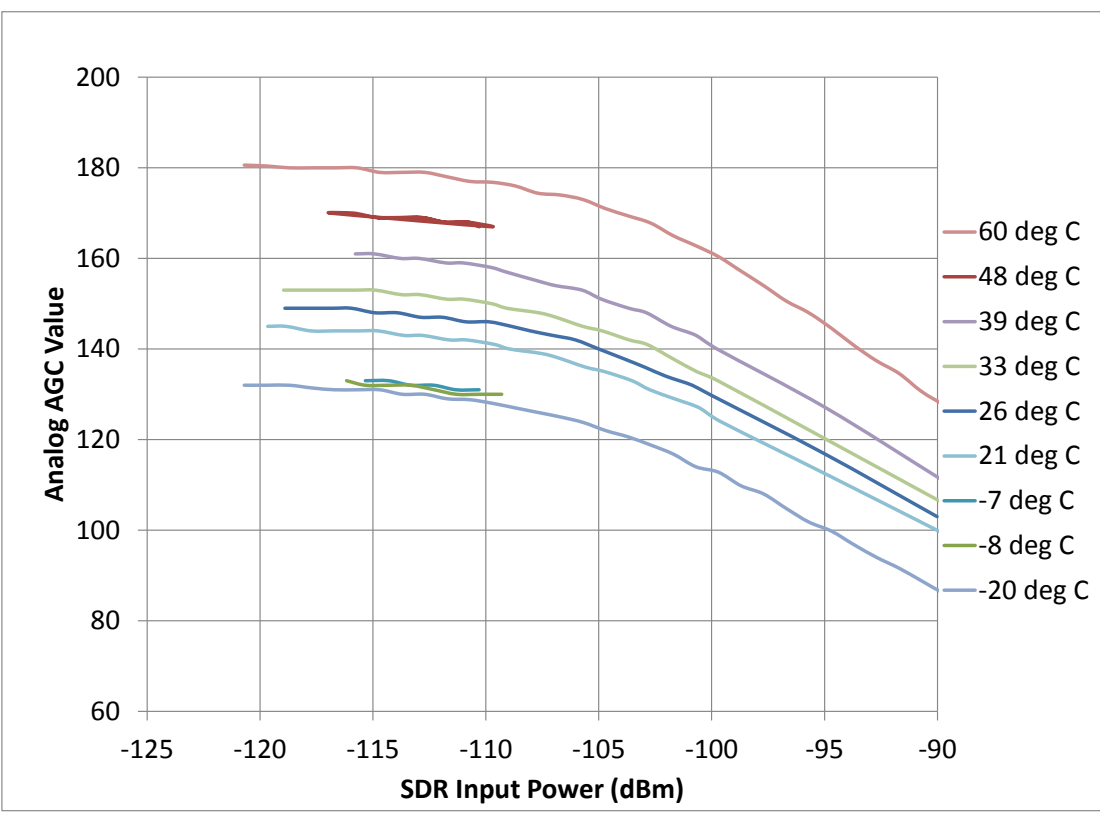

\section{Digital AGC}

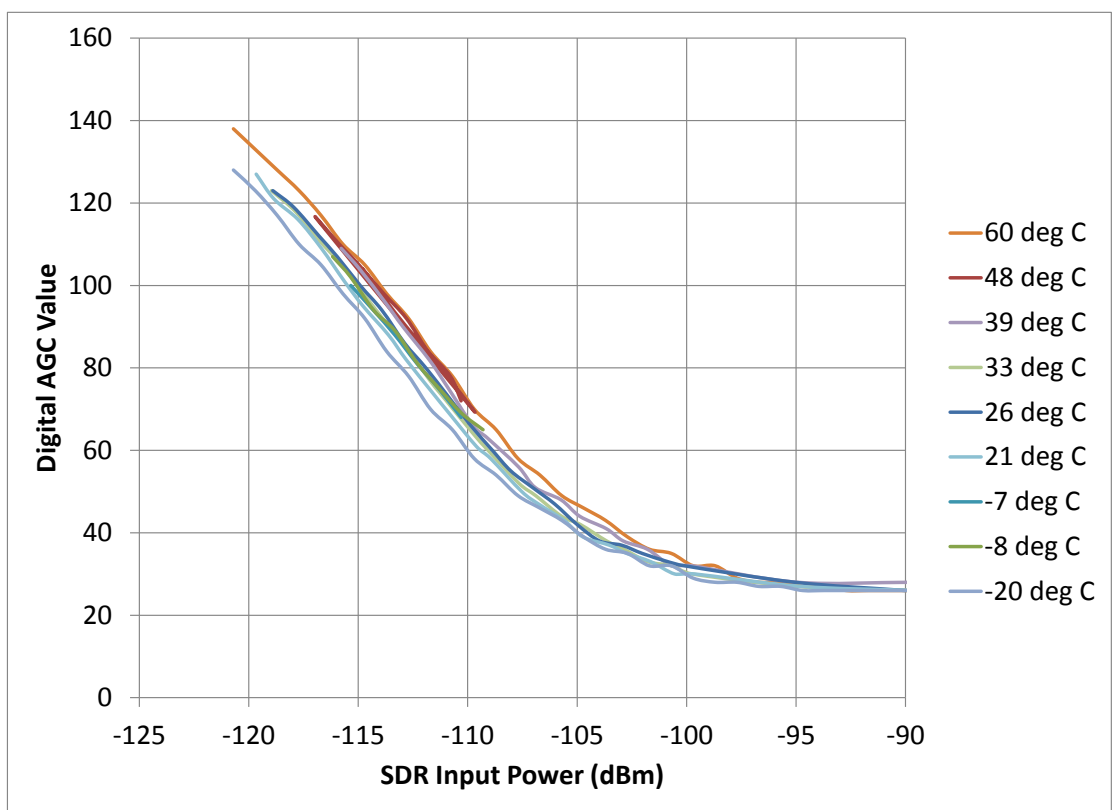

- Both analog and digital AGCs vary over temperature. The analog AGC variation is more significant. 
SDR INPUT POWER ESTIMATOR DESCRIPTIONS 


\section{Straight Line Estimator Algorithm Description}

- Straight line equations created to estimate power based on linear region of digital AGC

- 3 equations created for each waveform in 3 temperature regions:

- Cold: $\quad<10^{\circ} \mathrm{C}$

- Ambient: $10^{\circ} \mathrm{C}-35^{\circ} \mathrm{C}$

- Hot: $\quad>35^{\circ} \mathrm{C}$

- SDR input power range limited to linear region of the digital AGC

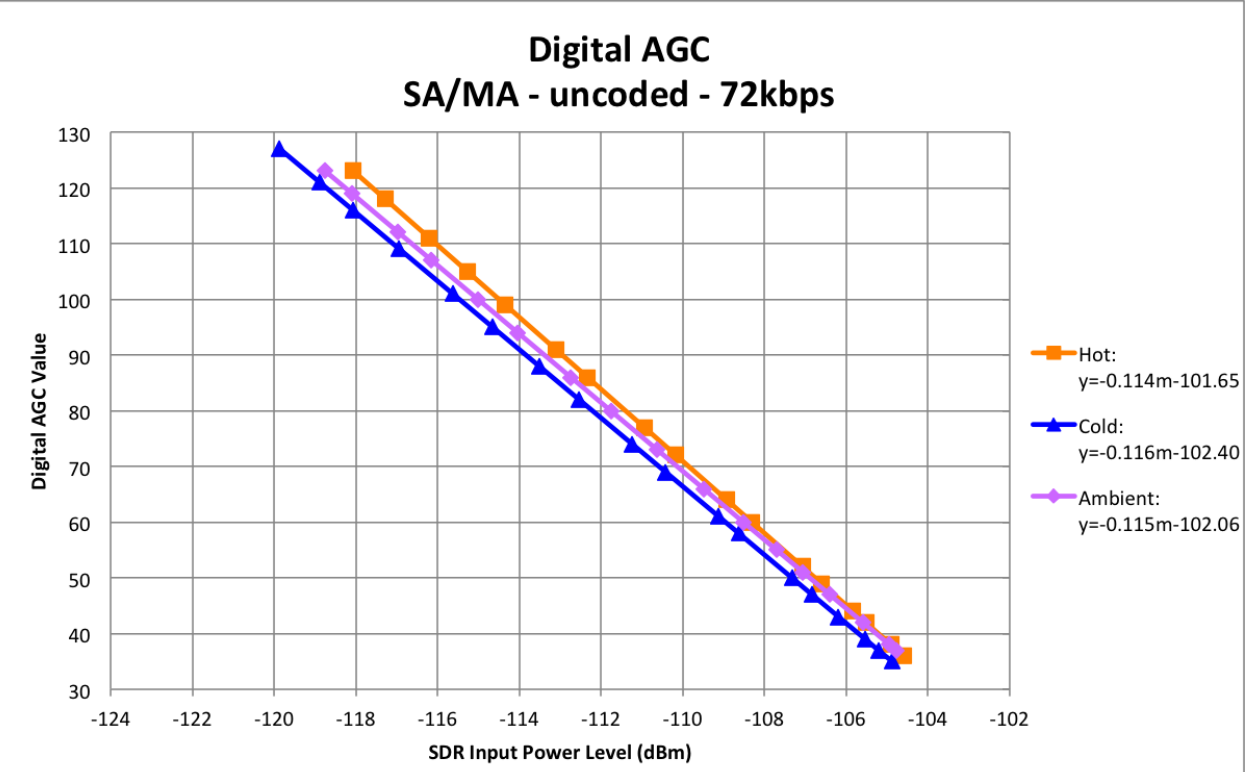




\section{Adaptive Linear Combiner Estimator Block Diagram}

1. $X=[D A G C$ AAGC Temp 50]

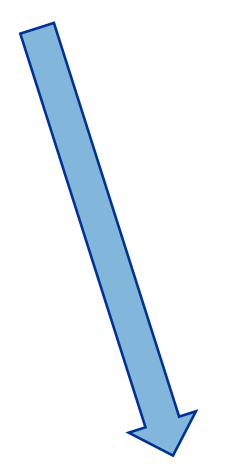

Inputs $(X)$

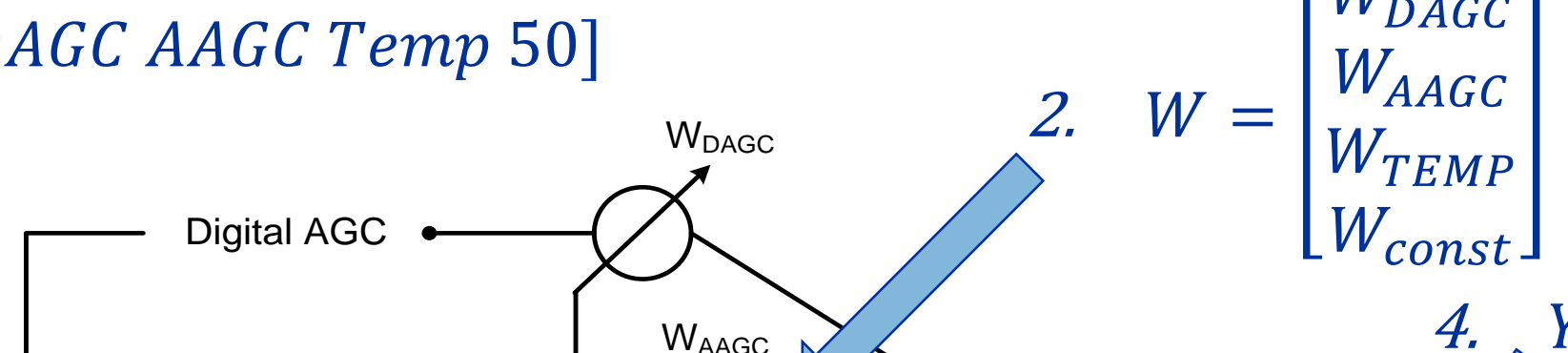

Analog AGC

Baseplate

Temp

Constant

LMS

Filter

$$
\text { 4. } Y_{n}=W_{n} X
$$




\section{Adaptive Linear Combiner Estimator Training Algorithm Description}

- Input the training data set

- Sort the data into 3 temperature bins

- Cold: $\quad<10^{\circ} \mathrm{C}$

- Ambient: $\quad 10^{\circ} \mathrm{C}-35^{\circ} \mathrm{C}$

- Hot: $\quad>35^{\circ} \mathrm{C}$

- Randomize the data in each bin

- Initialize the weight vector, W

- Compute the weight vector for each temperature bin

- Repeat the previous step until the weight vector converges

- Calculate the estimated output power 


\section{Adaptive Linear Combiner Estimator Membership Functions}

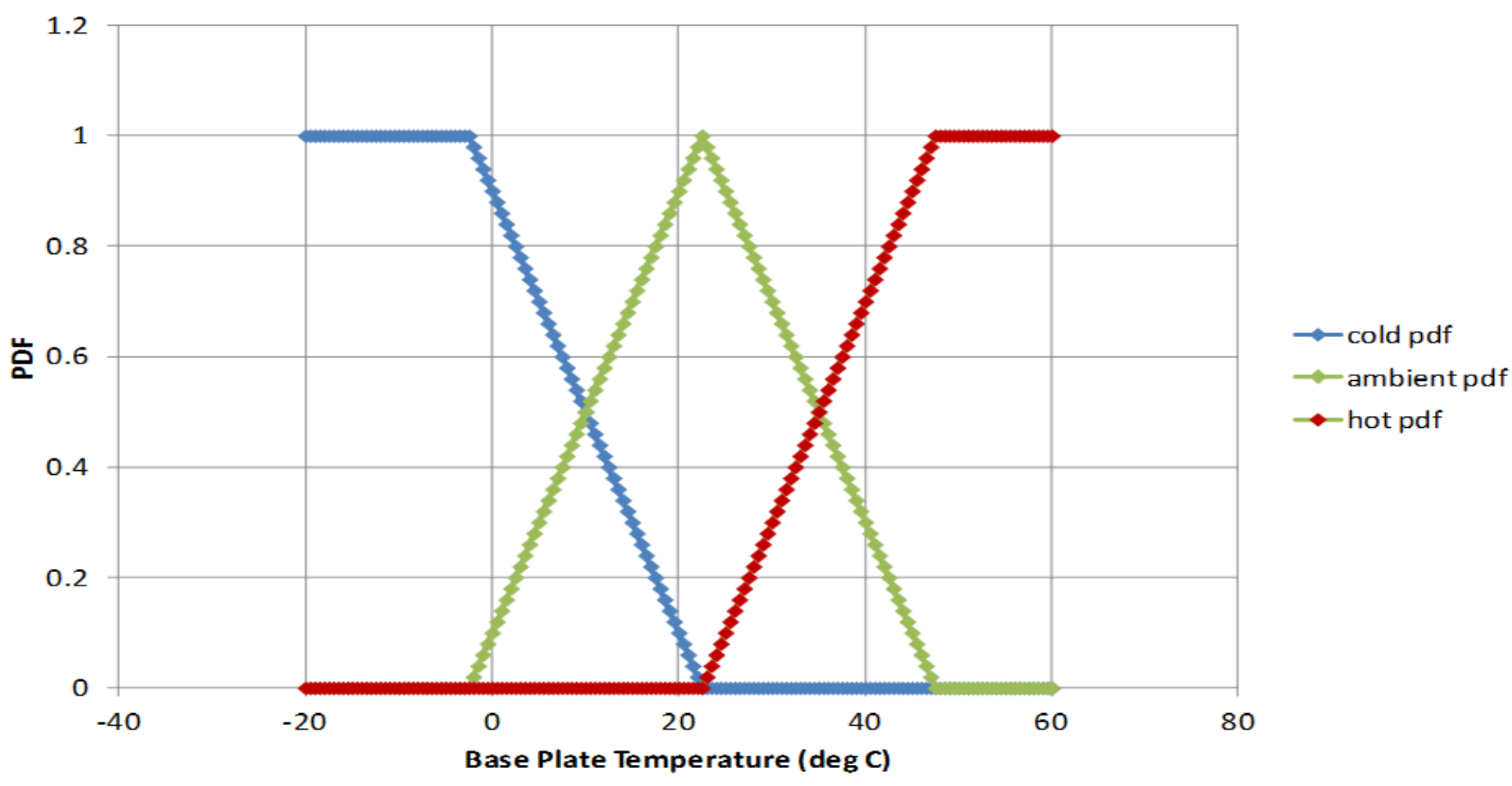

- SDR input power is a function of 2 temperature bins. For example, at $17.5^{\circ} \mathrm{C}$ :

$$
Y=.2 W_{c} X+.8 W_{a} X+0 W_{h} X
$$




\section{Neural Network Estimator Block Diagram}

1. $X=[D A G C A A G C$ Temp WFID T]

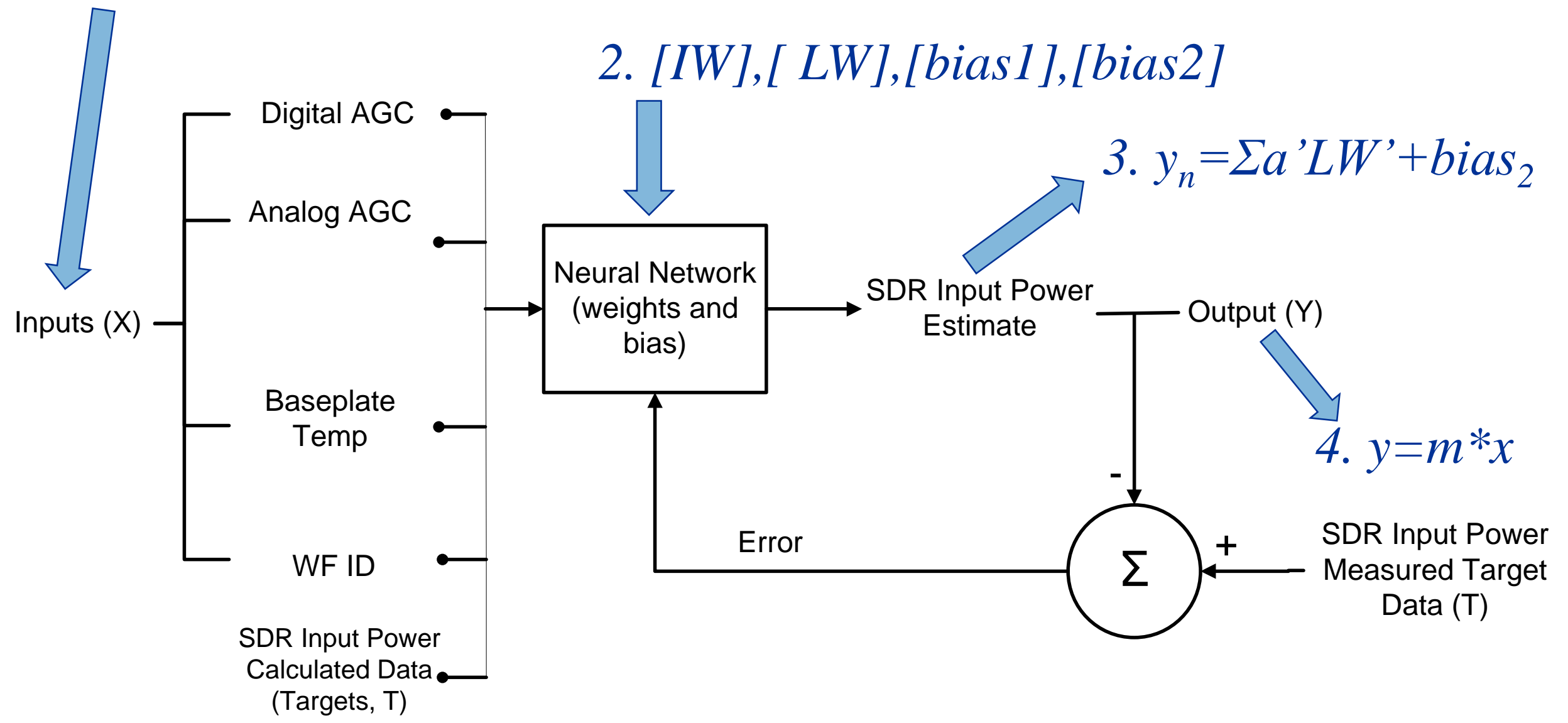




\section{Neural Network Estimator Algorithm Description}

- Input the training data set

- Train neural network $(60 \%$ data used for training)

- Simulate neural network (20\% data used for validation)

- Obtain weights and bias

- Compare the output $(Y)$ to SDR input power measured target data, $T$.

- Analyze the error; train and simulate the neural network to obtained new weights and bias if necessary. 


\section{Neural Network Estimator} Regression Analysis

Training

\section{Regression Plot}

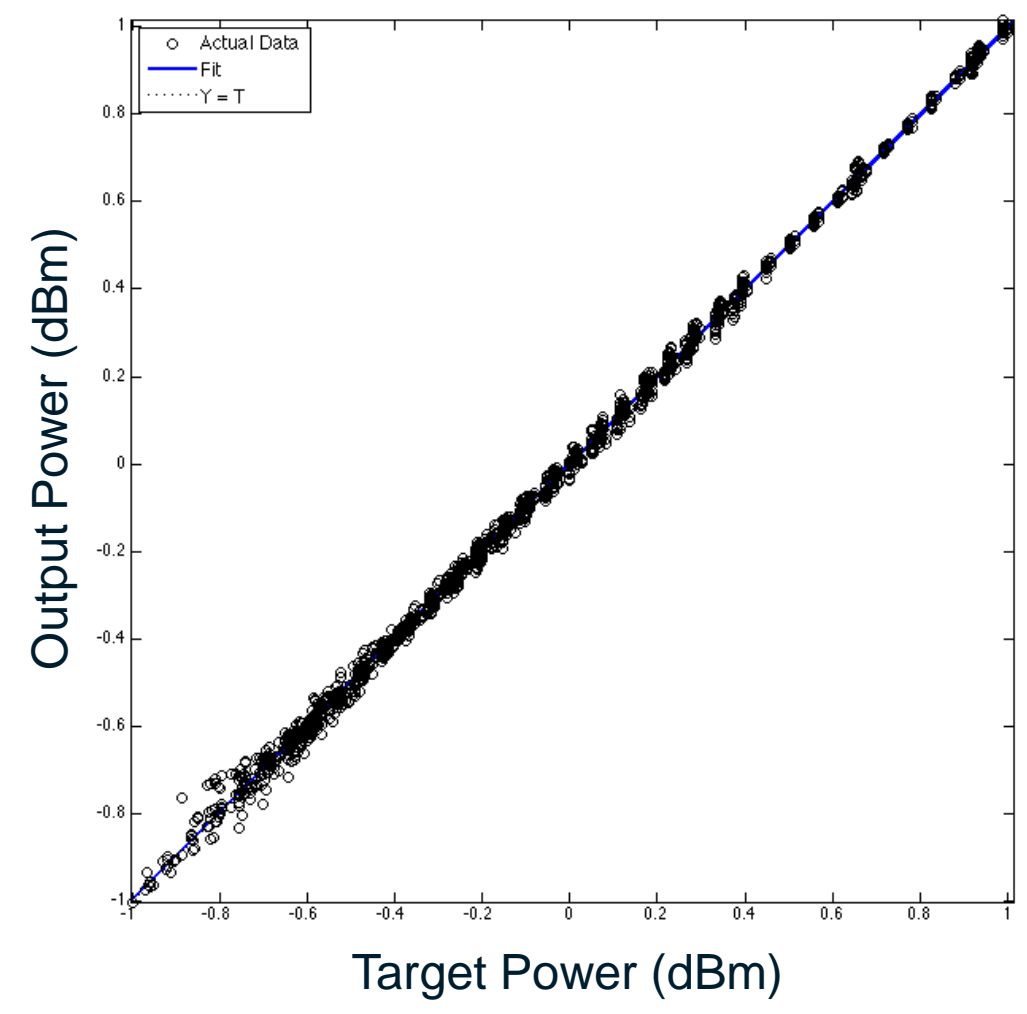

Final

\section{Regression Plot}

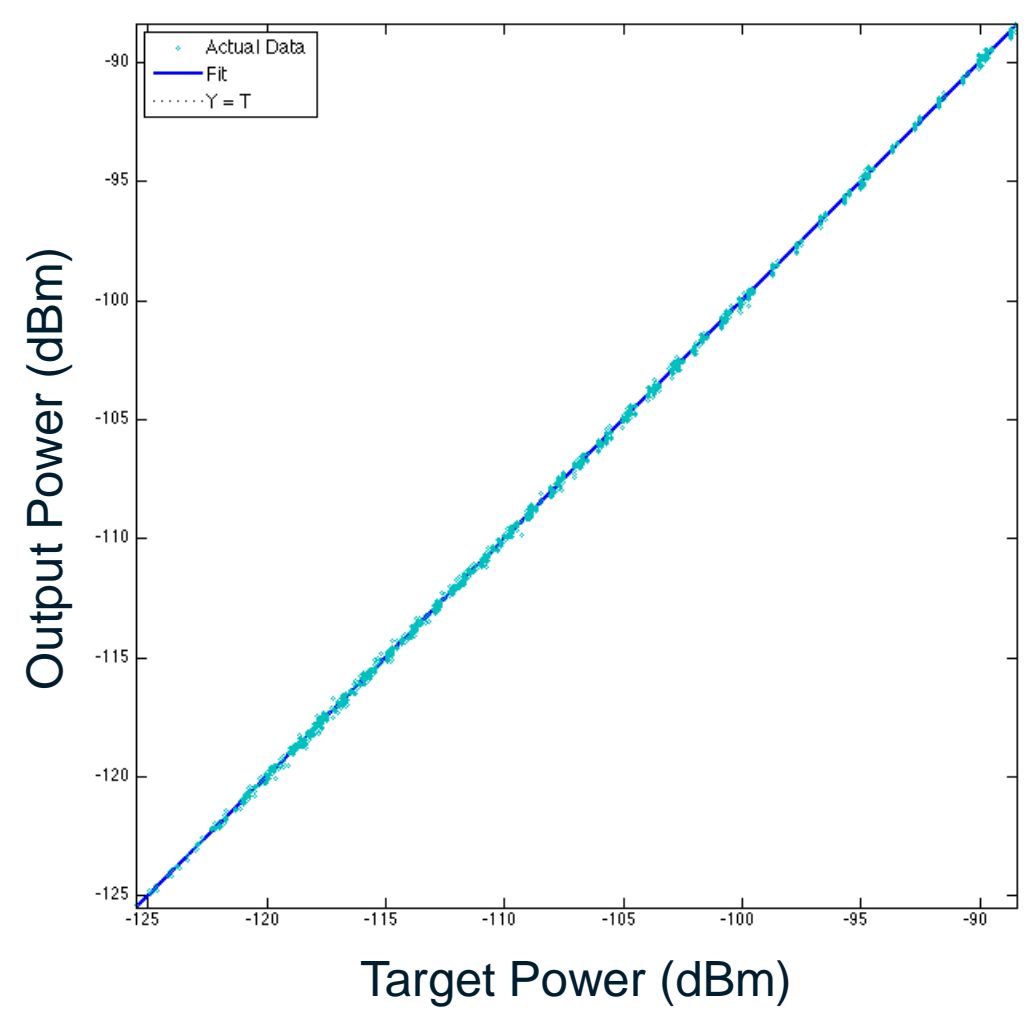

The training process is repeated until there is a good fit between the target and estimated power. 


\section{ESTIMATOR ERROR ANALYSIS}




\section{Histogram Error Analysis}

\section{Straight Line}

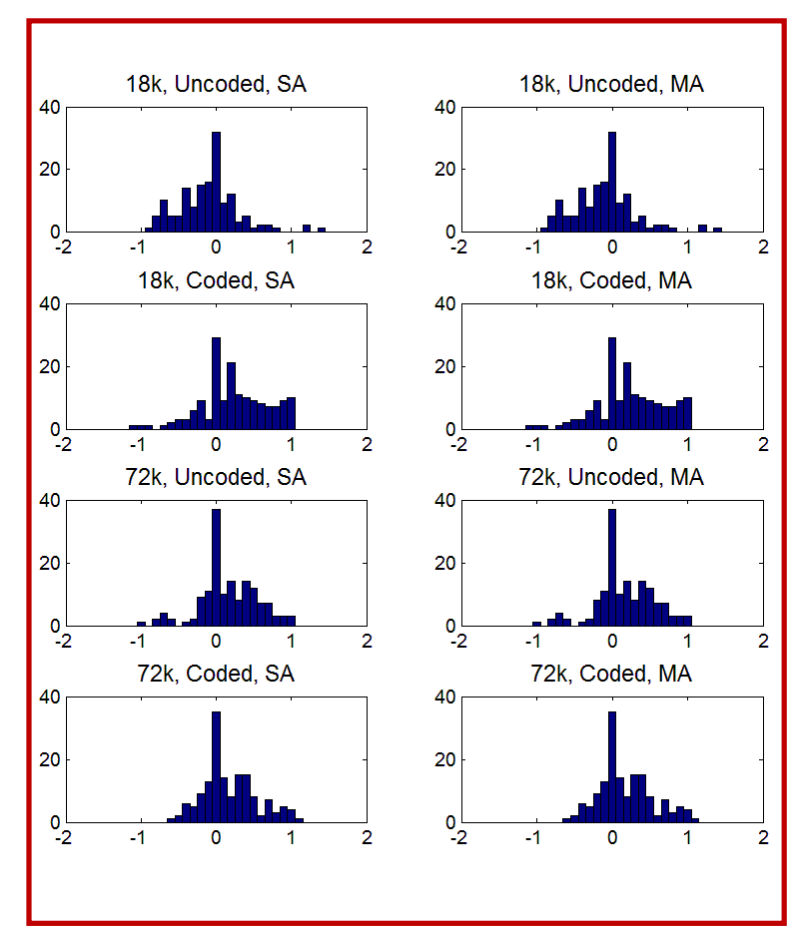

Linear Adaptive

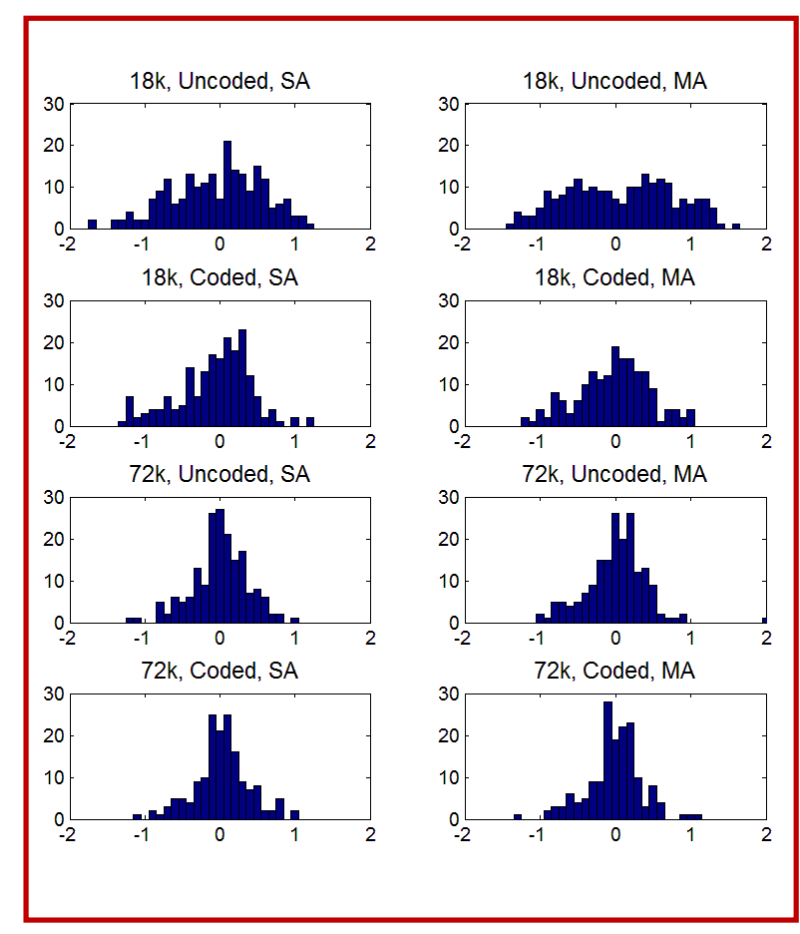

Neural Network

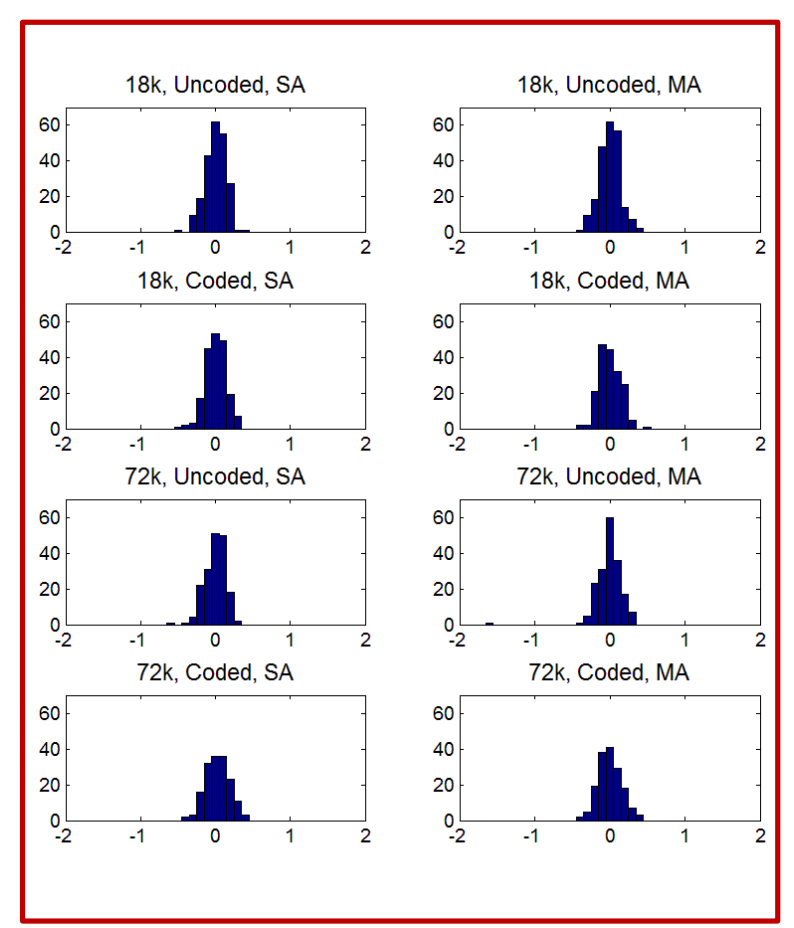

The histograms show that the neural network estimator has the lowest error $(+/-0.5 \mathrm{~dB})$, while the straight line and linear adaptive estimators are about the same (+/- $1.0 \mathrm{~dB})$. 


\section{Regression Error Analysis}

\section{Straight Line}

Linear Adaptive

\section{Neural Network}

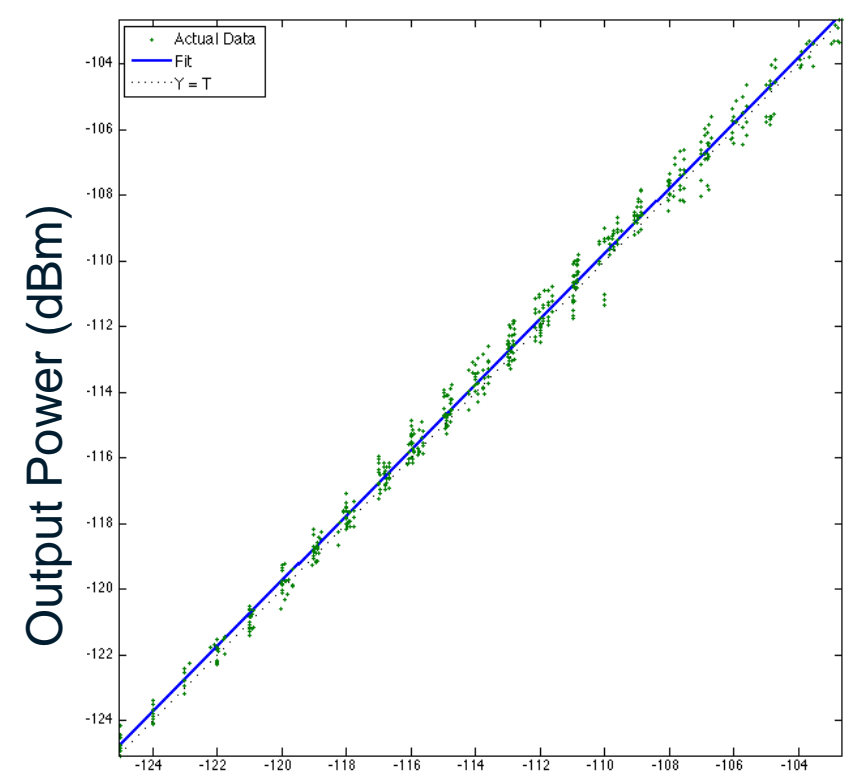

Target Power (dBm)
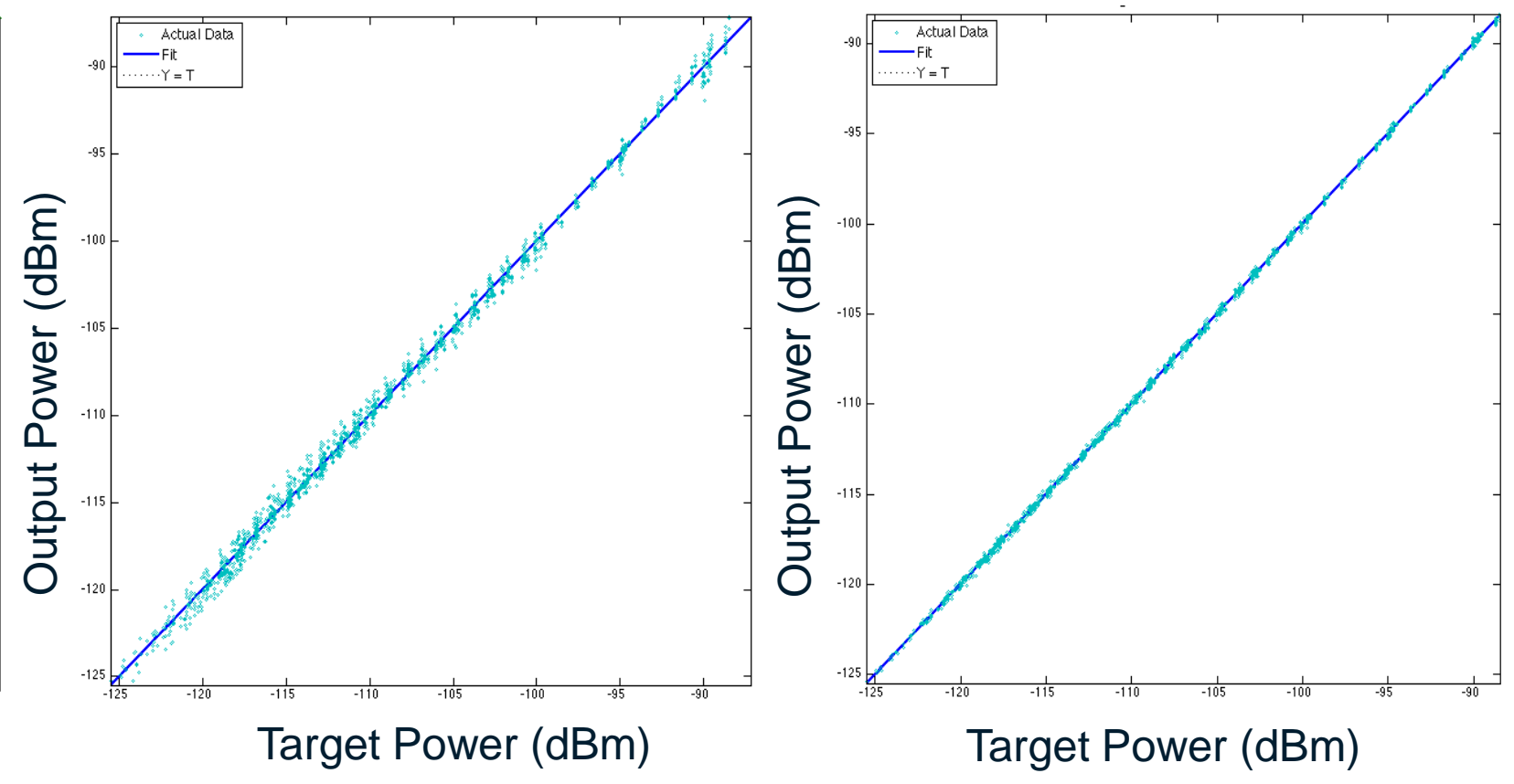

The straight line estimator and linear adaptive estimator have about the same error, but the linear adaptive has a higher SDR input power level (-90 dBm). 


\section{ON-ORBIT TESTING} EXPERIMENTAL RESULTS 


\section{On-orbit Testing Experimental Results}

GD SDR Checkout 09/26/2012

\section{$18 \mathrm{kbps} /$ uncoded/SA waveform, 7.5-8.5 ${ }^{\circ} \mathrm{C}$}

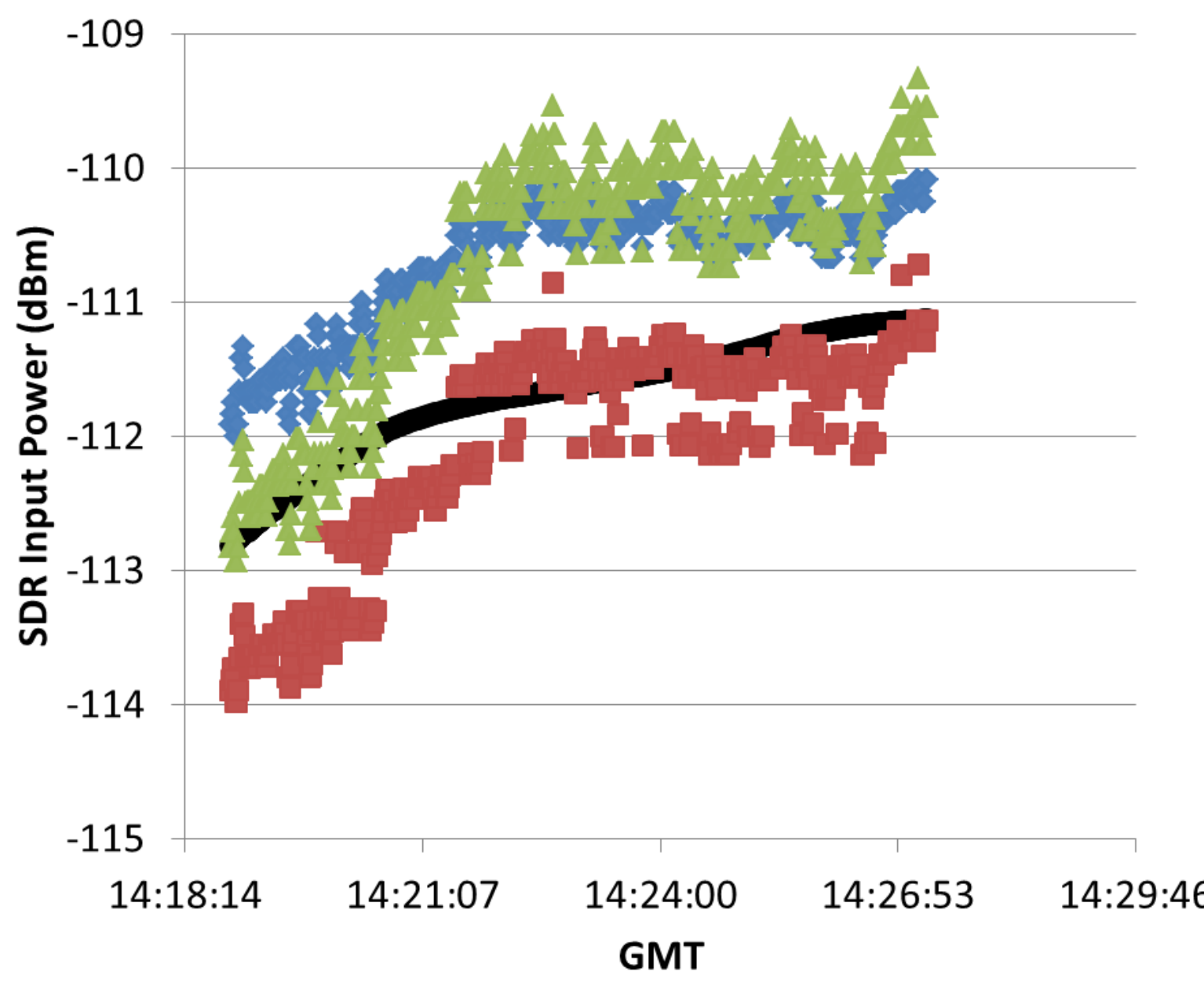

The estimators were implemented in the SCaN Testbed Ground Software.

- Predicted Power

- Straight Line Power

- Linear Adaptive Power

$\triangle$ Neural Network Power

Initial test results show all three estimators are within $2 \mathrm{~dB}$ of predicted. 


\section{On-orbit Testing Experimental Results}

\section{GD SDR Checkout 09/13/2012}

$18 \mathrm{kbps} /$ uncoded/SA waveform, $5.5-7.3^{\circ} \mathrm{C}$

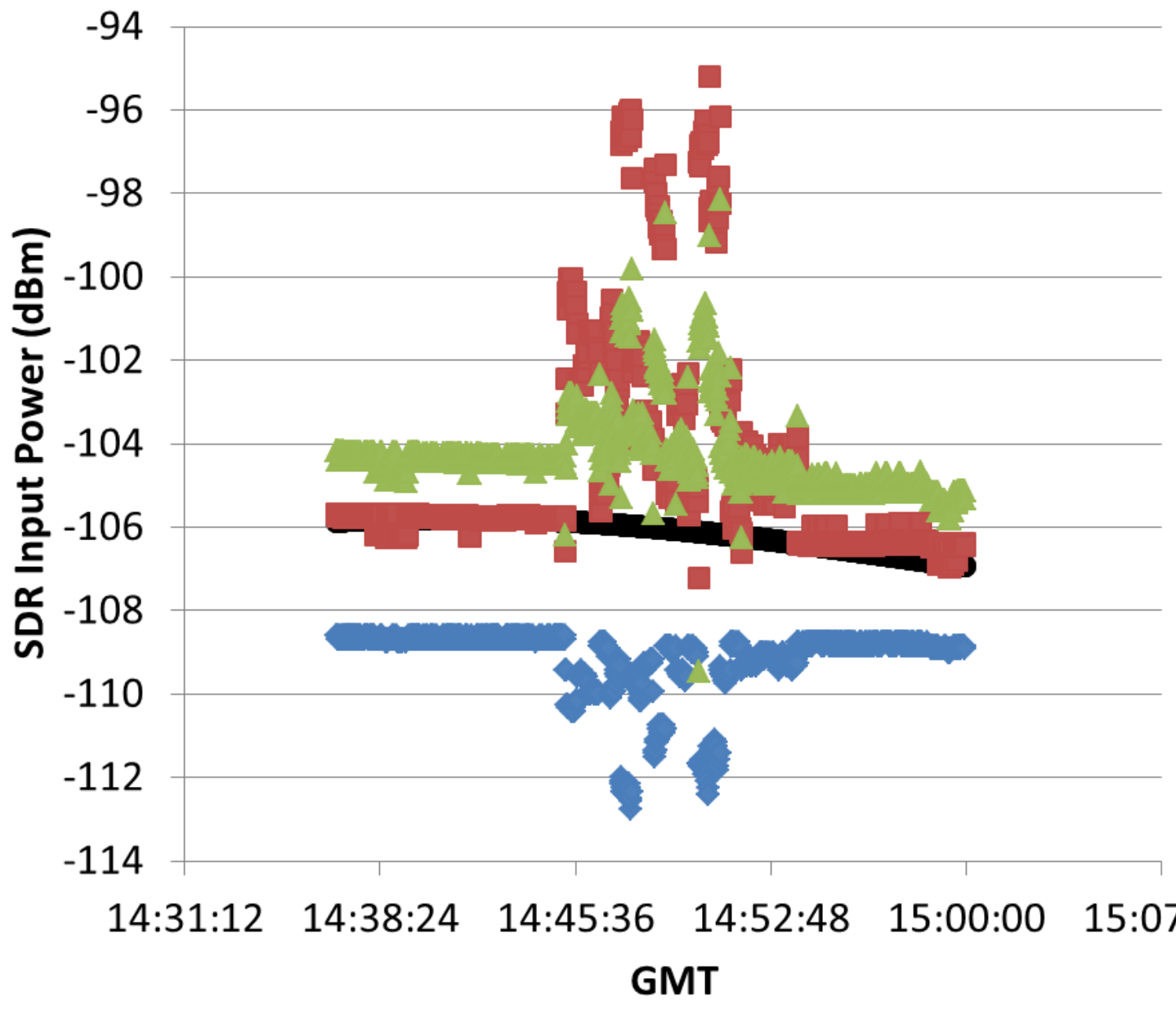

- Predicted Power

- Straight Line Power

- Linear Adaptive Power

$\triangle$ Neural Network Power

An unknown interferer is shown in the middle of this event. 


\section{Summary / Future Work}

\section{Summary}

- 3 estimators have been implemented and tested on the ground

- Initial on-orbit tests indicate that the estimators are within $2 \mathrm{~dB}$ of predicted SDR input power

- Algorithm dependence on the AGCs can lead to invalid results in the presence of interfering signals

\section{Future Work}

- Continue to characterize the SDR input power algorithms during on-orbit operations on ISS

- Utilize the engineering model (EM) characterization data to create SDR input power estimators for the EM

- A method for extending these algorithms for future waveforms could be developed 


\title{
Questions?
}

\author{
jennifer.m.nappier@nasa.gov \\ 216-433-6521
}

